\title{
Причина расхождения экспериментальных значений высоты барьера на контакте металл-полупроводник
}

\author{
( Ш.Г. Аскеров, Л.К. Абдуллаева, М.Г. Гасанов
}

Бакинский государственный университет, НИИ проблем ффизики, AZ-1148 Баку, Азербайджан

E-mail: ashahlar@hotmail.com

(Получена 20 сентября 2016 г. Принята к печати 11 октября 2016 г.)

\begin{abstract}
Сделана попытка объяснить причину расхождения высоты барьера для одного и того же контакта металл-полупроводник в работах различных авторов. Предполагалось, что эта проблема в основном связана со структурной неоднородностью металла, в результате чего контакт становится параллельным соединением многочисленных субконтактов, имеющих различные параметры. Для выявления влияния неоднородности металла на свойства контакта исследована зависимость высоты барьера диодов Шоттки от площади контакта. Предполагалось, что в случае контакта монокристаллического полупроводника с поликристаллическим металлом с ростом площади растут степень неоднородности и соответственно число субконтактов.
\end{abstract}

DOI: $10.21883 /$ FTP.2017.05.44418.8363

\section{1. Введение}

Согласно идеальной модели [1,2], высота барьера диода Шоттки $\Phi_{b}$ определяется разностью между работой выхода металла $\left(\Phi_{m}\right)$ и электронным сродством $(\chi)$ полупроводника:

$$
\Phi_{b}=\Phi_{m}-\chi
$$

В случае $n$-полупроводника контакт металл-полупроводник (КМП) должен обладать диодными характеристиками, если $\Phi_{b}>0$, и омическими, если $\Phi_{b}<0$. Кроме того, как следует из формулы (1), $\Phi_{b}$ должна линейно зависеть от работы выхода металла. Однако эти очевидные выводы не подтверждаются на практике. Согласно модели Шоттки, высота барьера на контакте данного металла с данным полупроводником должна иметь постоянное значение. На самом же деле значения высоты барьера, найденные для одного и того же КМП разными авторами, весьма различны и меняются в довольно широком диапазоне. В литературе, посвященной физике контакта металл-полупроводник, диод Шоттки (ДШ) часто называют „полупроводниковым диодом Шоттки“, т.е. ролью металла полностью пренебрегают. Иначе говоря, в большинстве случаев металл рассматривается как пассивный компонент КМП.

Эти обстоятельства и целый ряд других накопившихся за последние годы экспериментальных фактов показывают, что однородная модель Шоттки не в состоянии объяснить процессы, происходящие в КМП, и проблема в настоящее время остается нерешенной.

Целью данной работы является выяснение причины расхождения экспериментальных значений высоты барьера ДШ, полученных различными авторами для одних и тех же диодных структур.

Для решения поставленной задачи была изучена зависимость высоты барьера диодов Шоттки от площади контактов.

Необходимо отметить, что недостатком однородной модели является лежащее в ее основе допущение од- нородности границы раздела (ГР) в двух измерениях. Как следствие этого считается, что параметры КМП постоянны вдоль поверхности раздела. Очевидно, что такое рассмотрение не полностью отражает реальную ситуацию, поскольку ГР реальных КМП неоднородна по разным причинам (поликристалличность металла и дефекты в полупроводниках). Нам кажется, что все вышеперечисленные проблемы можно объяснить, если учесть роль микроструктуры металла в процессах, происходящих в КМП.

Известно, что важными эмиссионными параметрами ГР металл-вакуум являются работа выхода $(\Phi)$, постоянная Ричардсона $(A)$, и поэтому их определению уделяют большое внимание [3]. Такая точка зрения справедлива и для ГР КМП. Для одних и тех же контактных структур эти параметры определены в [4,5], и показано, что экспериментальные значения высоты барьера КМП меняются в широком интервале. Широкий диапазон изменения экспериментальных значений $A$ и $\Phi$ создают трудность для выявления среди них более или менее истинных значений как для границ металл-вакуум, так и для границ металл-полупроводник.

Анализ экспериментальных значений высоты барьера и постоянной Ричардсона для одних и тех же диодных структур показал, что между величинами $A_{i}$ и $\Phi_{i}$ (где $A_{i}$ и $\Phi_{i}$ - параметры данного эмиттера, определенные различными авторами) имеется корреляционная зависимость, которая выражается формулой [4]

$$
A_{i} e^{-\Phi_{B i} / k T}=B=\text { const. }
$$

Отметим, что аналогичная корреляционная зависимость имеет место и для ГР металл-вакуум. Нетрудно заметить, что $B$ имеет размерность постоянной Ричардсона и равняется ей при условии, что $\Phi_{i}=0$ или $T=\infty$. Из формулы (2) следует, что $\Phi$ является необходимым, но не достаточным параметром для описания эмиссионной характеристикой ГР. Эмиссионные свойства границы 


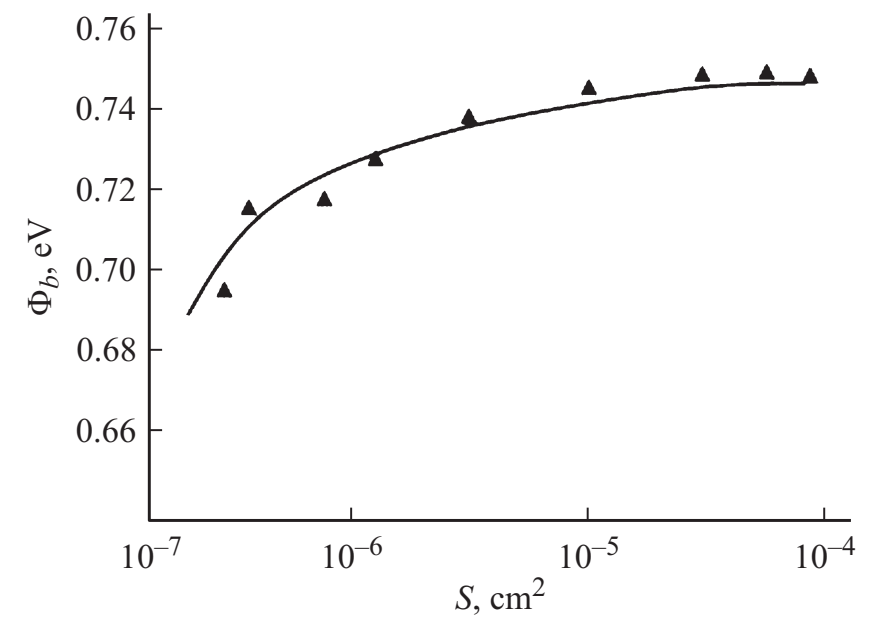

Зависимость высоты барьера ДШ $\mathrm{Al}-n-\mathrm{Si}(111)$ от площади контакта.

раздела металл-полупроводник (или металл-вакуум) можно описать либо через $A$ и $\Phi$, либо постоянной $B$. Высота барьера (работа выхода) и постоянная Ричардсона взаимно коррелированы для рассматриваемой ГР. Другими словами, параметр $B$ полностью описывает эмиссионные свойства границы раздела различных фаз, в том числе поверхности. Например, в работе [4] показано, что для эмиттера из $\mathrm{W}$ и $\mathrm{Al}-n-\mathrm{Si}$ ДШ постоянная $B$ имеет значения $3.6 \cdot 10^{-5}$ и $4 \cdot 10^{-10} \mathrm{~A} / \mathrm{cm}^{2} \cdot \mathrm{K}^{2}$ соответственно.

Можно предположить, что и в случае КМП микроструктурное разнообразие металла играет важный роль в процессах, происходящих в контакте. Как показано в предыдущих работах [4-8], в таком случае КМП можно представить как параллельное соединение многочисленных элементарных контактов [8]. Нетрудно представить, что в таком случае поведение контакта должно зависеть как от количества параллельно соединенных субконтактов, так и от их индивидуальных параметров.

В случае двухдиодного контакта, согласно [7], высота барьера выражена формулой

$$
\bar{\Phi}=\frac{\Phi_{1} S_{1}+\Phi_{2} S_{2}}{S_{1}+S_{2}}=\omega_{1} \Phi_{1}+\omega_{2} \Phi_{2}=\sum_{i=1}^{n} \omega_{i} \Phi_{i} .
$$

Здесь $\bar{\Phi}-$ усредненная по поверхности высота барьера, $\Phi_{1}$ и $S_{1}$ - высота барьера и площадь первого диода, $\Phi_{2}$ и $S_{2}$ - высота барьера и площадь второго диода; $\omega_{1}$ и $\omega_{2}$ - относительные площади диодов. Как видно из формулы (3), высота барьера неоднородного контакта $\bar{\Phi}$ зависит от относительной площади субдиодов.

Для проверки справедливости данного предположения была изучена зависимость высоты барьера $\mathrm{Al}-n-\mathrm{Si}(111)$ диодов Шоттки от площади контакта [5], которая представлена $S$ на рисунке. Как видно из рисунка, с ростом площади диодов высота барьера $\Phi_{b}$ растет.

Очевидно, что с ростом площади контакта растет число субдиодов, образующих общий контакт и имею- щих различные параметры. Нам кажется, что поликристалличность металла переводит однородный контакт в неоднородный. Наличие зависимости $\Phi_{b}(S)$ косвенным образом доказывает влияние поликристалличности (микроструктуры) металла [5] на свойства ДШ. Считаем, что с ростом площади диода растет количество параллельно соединенных субдиодов, т.е. с ростом площади растет сложность системы.

Поэтому свойства неоднородного контакта должны сильно отличаться от свойств однородного, как это следует из теории сложных систем [9]. Каждая ГР КМП индивидуальна и имеет свои собственные параметры.

\section{2. Заключение}

Таким образом, выявлена роль металла в работе диода Шоттки и показано, что металл является не менее активным компонентом КМП, чем полупроводник. Расхождение значений высоты барьера одних и тех же диодных структур, полученных различными авторами, объяснено структурным разнообразием границы раздела.

Показано, что Ф является необходимым, но не достаточным параметром для описания эмиссионной характеристикой ГР. Эмиссионные свойства границы раздела металл-полупроводник (или металл-вакуум) можно описать либо через $A$ и $\Phi$, либо через постоянную $B$.

Сделан вывод о том, что наблюдаемая зависимость $\Phi_{b}(S)$ является влиянием неоднородности ГР, инициируемой металлическим компонентом контакта металл-полупроводник. С ростом площади растет число субдиодов, и в результате контакт превращается в сложную систему. Полученные результаты объяснены с позиции неоднородной модели КМП, представляющей контакт как сложную систему, состоящую из параллельно соединенных многочисленных элементарных, однородных контактов.

Предполагаем, что на базе ДШ с поликристаллическим металлом можно экспериментально изучать закономерности сложных систем.

\section{Список литературы}

[1] С.М. Зи. Физика полупроводниковых приборов (М., Мир, 1984) ч. 1 , с. 34.

[2] П.Н. Крылов. Вестн. Удм. гос. ун-та. Физика, № 4, 1 (2006).

[3] В.С. Фоменко. Эмиссионные свойства материалов (Киев, Наук. думка, 1981) с. 146.

[4] Ш.Г. Аскеров. Радиотехника и электроника, 31 (11), 2296 (1986).

[5] Ш.Г. Аскеров. Изв. АН АзССР. Сер. физ.-техн. и мат. наук, № 1, 57 (1978).

[6] Ш.Г. Аскеров. Письма ЖТФ, 3 (18), 968 (1977).

[7] Ш.Г. Аскеров, Г.Г. Кадимов. Изв. АН АзССР. Сер. физ.-техн. и мат. наук, № 2, 21 (1986).

[8] Ш.Г. Аскеров. Матер. III Всес. науч.-техн. сем. (Рязань, 1984) c. 122. 
[9] А.Ю. Лоскутов, М.С. Михайлов. Основы теории сложных систем (Москва-Ижевск, 2007) с. 17.

Редактор Л.В. Шаронова

\section{The reason for difference}

in the experimental values of the contact metal-semiconductor barrier height

\section{Sh.Q. Askerov, L.K. Abdullayeva, M.H. Hasanov}

Baku State University, Institute for Physics Problem, AZ-1148 Baku, Azerbaijan

Abstract This paper in an attempt to explain the reason of difference between experimental values obtained by different authors at determination of barrier height in the same metal-semiconductor contact. This problem was assumed to be related to the structural heterogeneity of the metal-semiconductor interface. As a result a contact was considered as parallel connection of numerous subcontacts. To determine the effect of non-uniformity of the interface on the properties of metal-semiconductor contact the basic metall-semiconductor contact parameters are examined. It is supposed that with increasing contact area the degree of the heterogeneity and corresponding number of the subcontacts also increase. 